\title{
Growing Professionals in Science and Technology of Korea's new Marine Industry Sector
}

\author{
Ki Won Han ${ }^{1} \&$ Yohan $\mathrm{An}^{2}$ \\ ${ }^{1}$ Marine Policy Division, The Korea Maritime Institute (KMI), Busan, Republic of Korea. \\ ${ }^{2}$ Tongmyong University, Busan, Republic of Korea. \\ 1'kwhan@kmi.re.kr\&²accahn@tu.ac.kr \\ DOI: https://doi.org/10.37134/jcit.vol9.6.2019
}

\begin{abstract}
With consideration to research nature, scope of available materials and industrial feature, we investigate cultivation of professionals in the three new marine industries such as marine energy, marine bio-industry and submarine hydrothermal deposits development. More specific, we investigate trends of marine science and technology manpower at the national level in Korea nurturing policy to forecast mid and long term expert manpower demand and to respond to trends and forecasts of major fields. Cultivation of necessary professionals is an essential prerequisite for growth of new marine industry and its contribution to national economy. Because the new marine industry was recently introduced, the established system and policies for professionals in science and technology did not reflect demand for this new industry, which requires improvement. Since new marine industry is a new field, it is difficult for customized talent to be supplied directly from existing manpower training system. Therefore, it is necessary to cultivate talented people with fused thinking and ability. In the existing system, it is necessary to strengthen efforts to develop professional manpower with fusion competence, and it is also necessary to make policy efforts to build a new system such as cooperation process.
\end{abstract}

Keywords: New marine industry; Professionals; Science and Technology

\section{INTRODUCTION}

Human beings have used the ocean as a stage for mainly fisheries and shipping. However, with the rapid development of science and technology in the 20th century, the knowledge of the ocean has greatly increased and the usage of the ocean has expanded rapidly. New industrial fields for ocean are emerging in order to utilize abundant marine resources. These new marine industries have bright prospects to overcome advanced countries in terms of their efforts in the development phase or in the introduction phase. Specifically, the importance of the ocean is increasingly emphasized as a source of alternative energy such as natural gas and methane hydrate as well as algae, tidal power, temperature difference, bio, and wind power. The search for useful new materials such as the pharmaceutical industry has been mainly focused on the inhabitants of the land, but the possibility of marine life with large biodiversity is highlighted, and the interest is shifting to the sea.

In order to develop the emerging new marine industry, it is essential to nurture the necessary expertise in each field. In order to do so, it is necessary to first examine the system for training marine science and technology specialists. However, there is a growing concern about the imbalance in the supply of professional manpower, as the demand for domestic marine-related professional manpower is increasing, especially in the new marine industry. 
The marine industry features diversity that includes both primary and tertiary industries. In particular, new marine industries require research and development using industrial complexes and science and technology. Marine powers such as the United States, EU countries, Japan, and China are aware of the importance of marine science and technology and have established educational policies to nurture professional manpower. In order to secure competitiveness and to prevail in new marine industry, it is necessary to systematically establish and implement mid and long term expert manpower policies based on industry trends and forecasts.

With consideration to research nature, scope of available materials and industrial feature, we investigate cultivation of professionals in the three new marine industries such as marine energy, marine bio-industry and submarine hydrothermal deposits development. In addition, we estimate both demand and supply of professionals in marine science and technology at the national level in Korea based on various new marine industry researches such as the Korea Maritime Institute (hereinafter KMI), the Korea Institute of Marine Science \& Technology Promotion (hereinafter KIMST) and the Science and Technology Policy Institute (hereinafter STEPI) as well as the Korea Educational Statistics Service. More specific, we study trends of national science and technology manpower nurturing policy to forecast mid and long term expert manpower demand and to respond to trends and forecasts of major fields. Cultivation of necessary professionals is an essential prerequisite for growth of new marine industry and its contribution to national economy. Because the new marine industry was recently introduced, the established system and policies for professionals in science and technology did not reflect demand for this new industry, which requires improvement.

\section{DEFINITION OF NEW MARINE INDUSTRY}

The meaning of new marine industry is various, and its contents are inevitably different according to the times. The concept of new marine industry is still in flux, so there is no agreed definition and classification system, and it may have different meanings depending on the person who uses it.

The KMI research (2011) proposed by Kim et al defined the marine industry as a combination of traditional industries such as fisheries, shipbuilding, shipping, and port industries, and marine tourism and marine mining, and new industries such as equipment and construction, marine defense and public administration, R\&D and education. Traditional marine industries such as fisheries, shipping, port operation, and shipbuilding are in maturity and saturation phase in the development stage of the marine industry. New marine industries are in the early stages of development. In the classification of new marine industries, KMI (2011) classified the new marine industry by dividing it into spatial resources, mineral resources, biological resources, seawater resources, and energy resources. The new marine industries include marine equipment, offshore plant manufacturing, marine environmental cleanup and restoration, marine mining (abnormal spatial and mineral resources), marine chemical and pharmaceutical manufacturing, marine beverage manufacturing (abnormal bio and marine water resources), and marine energy industry (energy resources).

Another the KMI research (2011) operated by Hwang et al. defined that the marine industry is defined as economic activity in the waters for the purpose of protecting the marine environment, using marine space, and collecting marine resources, economic activities that 
produce essential production factors that are professionally used for such activities, and economic activities that are produced by economic activities in the waters as essential production factors that cannot be replaced. New marine industry is a new industry in the marine industry, and the new industry refers to the industry in the early stage or the introduction period in the development stage such as marine research and observation, coastal and marine space utilization, marine renewable energy, deep sea mineral resources development and marine biotechnology. On the other hands, the KIMST research (20110 done by Hwang et al. has adopted the marine industry as the major classification of marine extraction, marine manufacturing, marine construction and service industry.

Although new marine industries are proposed in various ways, it does not mean a specific industrial group, and it is very difficult to limit the category of new marine industries because new industries can be born in all fields due to the development of science and technology. China's "National Ocean Project Development Plan" has focused on eight new marine industries, mainly focusing on marine energy, mineral resources, marine bio, and marine equipment manufacturing. Japan is also spurring development of marine minerals, submarine oil and natural gas by establishing the 'Marine Energy and Mineral Resources Development Plan' in 2009. As such, new marine industries are rapidly becoming commercialized in marine resources, and marine energy, mineral resources, marine bio, and marine equipment are classified as major industries.

\section{DEMAND FOR PROFESSIONALS IN NEW MARINE INDUSTRY}

Demand by sector in the training of marine science and technology specialists is rarely systematic, so it can be obtained through Delphi survey by expert survey or qualitative survey by consultation. In particular, it is difficult to forecast mid-to-long-term demand in recent growth areas such as new marine industries, and it is difficult to predict short-term forecasts within five years because in new marine industry, it is a newly emerged field, so there is a limitation that systematic analysis is difficult due to lack of past data. Long-term historical data corresponding to long-term demand forecasts are needed, but there is no accumulated data for a new marine industry even if data are available. In this situation, reliance on sectoral industry outlook data can lead to excessive demand forecasting, which could lead to data reliability problems. Therefore, this study systematically investigates the workforce based on the scale of output by each industry, the employment coefficient, and the growth rate presented in the KMI (2013).

In the KMI research (2013) operated by Han et al., the marine energy industry is divided into three areas: offshore wind power generation, wave power generation, tidal power generation, tidal power generation, and tidal power generation in consideration of the nature of the research, the importance of industry. The marine renewable energy industry remained in the R\&D stage until 2008, so the direct output could not be derived. Thus, the marine renewable energy industry can estimate the number of employees in combination with the marine civil engineering and construction industry and the marine equipment and equipment industry, which are closely related. The marine civil engineering and construction industry includes activities such as port facilities, sea structures and cable installation, and marine special bridge construction. The marine equipment and equipment industry includes machinery, electrical and electronic equipment and precision equipment. By 2020, Won (2013) 
forecasts annual average annual growth rates of marine civil engineering and construction industry and marine equipment and equipment industry are 5\% and $4.49 \%$, respectively. Therefore, of the total 46,107 manpower employed in the marine renewable energy industry in 2020, a total of 23,976 manpower can be estimated by applying $52 \%$ of the ratio of master and doctoral graduates in the marine power sector.

Submarine hydrothermal deposits development are emerging as commercial deep-sea mineral resources, and various mineral resources (gold, silver, copper, zinc, etc.) formed during the discharge of hydrothermal water through the subterranean crust are developed. In terms of economic value, the IMO estimates the value of seabed hydrothermal deposits at about $\$ 489$ to $\$ 1,360$ per ton. Korea is actively developing submarine hydrothermal deposits in the South Pacific Islands, especially in Fiji and Tonga EEZ. It is expected that the output of submarine hydrothermal exploration will amount to US\$2,314.8 billion in 2020, which is estimated to be very bright.

The development of submarine hydrothermal deposits development is the most closely related to marine mining. As of 2008, the output of marine mining was US\$ 378 million, and the number of employed workers per US\$ 1 million was total 1,945 workers. Since most of the output of marine mining is composed of crude oil, natural gas, salt, sand and gravel, the number of people employed in the development of pure seabed hydrothermal ore will be far below the 1,945 marine mining workers. Estimates of the manpower required for the submarine hydrothermal deposit development in 2020 can be estimated to be about 11,700 people out of total number of 83,577 manpower if $14 \%$ of the share of the output of the submarine hydrothermal deposit development accounts for the estimated manpower of the marine mining industry in 2020.

The manpower structure of the submarine hydrothermal deposits development is presumed to be most closely related to the extraction of crude oil and natural gas from the existing marine mining industry. According to the STEPI research (2011) proposed by Hong et al., there are 2,480 technicians, 620 researchers, and 500 support workers among total number of 3,600 manpower (including petroleum gas and general minerals) needed for overseas resource development in Korea. Therefore, it can be assumed that the proportion of research personnel that can be classified as skilled technical personnel accounts for about $17 \%$ of the total, and if this ratio is applied to the 11,700 manpower demand of the submarine hydrothermal deposit development in 2020, required demand with professional manpower can be 2,015 people.

The size of the bio industry in Korea, including the marine bio industry, was estimated at about US $\$ 3.3$ billion in 2008, according to the National Statistical Office survey. However, the marine bio industry in Korea is very small, and the global market share in 2008 is only about US\$ 48 million, which is about $1.6 \%$ of the total, and only 25 companies are listed in the KOSDAQ. Based on this, it can be estimated that the marine bio industry in Korea accounts for about $14 \%$ of the total bio industry. The number of workers in the bio industry in Korea was about 20,520 people (the Korean Bio Industry Statistics 2008). Therefore, the number of employees in the marine biotechnology industry can be estimated at 2,873 , which is $14 \%$ of the total number of employees in the bio industry. The marine bio industry is evaluated as a very fast-paced industry, and the EU Science Foundation expects annual growth rate of marine bio industry to be over $10 \%$ and BizAcumen to grow at an average annual rate of $4.3 \%$. The domestic production of the marine bio industry in 2020 is estimated to be about US $\$ 350$ 
million and the demand for manpower is estimated to reach 21,634. According to the National Statistical Office (2011), the proportion of highly educated people is high, with $7 \%$ for doctoral students, $25.7 \%$ for masters and $29.8 \%$ for bachelors. Therefore, if the ratio of professional manpower in the marine biotechnology industry is estimated to be the same as that of the bio industry, it can be estimated that about 7,074 professional manpower of more than three or more will be among the total number of 21,634 manpower in the marine bio industry in 2020 .

As we have seen, there are many uncertainties in predicting demand for mid and longterm experts in new marine industries. The most important reason is that it is difficult to predict the future in a situation where it is impossible to obtain sufficient historical data. On the other hand, there were many difficulties in anticipating supply side as well as demand forecast of professional manpower. Even if they are from specific majors in related departments, they are not necessarily entering new marine industry by a certain percentage. Therefore, changes in the number of graduates and departments of departments are not directly linked to the increase or decrease in the supply of skilled human resources.

\section{FORECASTS OF PROFESSIONALS IN NEW MARINE INDUSTRY}

As of 2020, the demand for professional manpower in the three areas of new marine industry is estimated at 33,038 manpower, and the demand for total manpower is expected to be 79,441 manpower. Assuming that the period of occupation of new marine industry professionals is about 15 years, the total number of experts to be supplied annually is about 2,203 manpower. On the other hand, as of the end of 2012, the number of master and doctoral graduates from new marine industry related departments was 79,441 manpower. Assuming that in 2020, the number of professionals similar to that of 2012 will be around $7 \%$ of the total number of masters and doctoral graduates who graduate from marine industry related departments per year, which is the minimum number of 2,203 manpower to be supplied to three new marine industries. Assuming an increase in the number of graduates, the number of graduates expected in 2020 will be 36,342 manpower, and the proportion of 2,203 manpower in the three areas of new marine industry will be $6.1 \%$. Conversely, if graduates decline by $10 \%$ from 2012 levels, the expected number of graduates will be 29,734 people and the percentage of new marine industry professionals will be about $7.4 \%$ per year. In the end, in order for new marine industry to develop smoothly in the mid- to long-term, it is expected that securing $6 \sim 8 \%$ of master's and doctoral graduates in new marine industry field will be a key task of training marine science and technology experts. Although this ratio is not large, it is not a straightforward goal considering the number of personnel entering other fields such as existing competent industries. Many mater and doctoral graduate will set their further position to universities and research institutes, and sometimes they will have jobs that are not related to their major. In the case of marine departments, many of them will advance into the existing marine industry. In the case of non-marine industries, fierce competition will be inevitable for securing manpower with other industries.

The supply of science and technology experts needed in new marine industry is not sufficient, and it will be a problem that the supply will continue to the present level. In particular, the supply of specialized human resources in new marine industry is lacking in quantity, so more professional workers should be released through domestic graduate schools. In the simple calculation above, the annual growth rate of the number of enrolled 
students was applied to the change of the number of graduate students in the master and doctorate, but the increase (decrease) of enrolled students would not exactly match the degree of graduation increase (decrease).

One fundamental limitation of this simple calculation is the selection of related departments. In this case, related information and expert advice have been drawn as much as possible for marine new industries. However, there are various ways to choose marine new industry related subject. In addition, it is a mistaken assumption that the proportion of students who graduate from the graduate school related to new marine industries is fixed. In the case of marine related students, many of them choose jobs that are not related to the sea. In particular, it is not possible to think that graduates from non-marine areas enter new marine industries at a certain rate. The rate of new marine industry selection among marine majors will change depending on the situation, which will be even worse for majors in the nonmarine sector. Therefore, it will be a policy issue to decide how to engage graduate students graduated from marine and non-marine related fields in new marine industries.

Therefore, it is necessary to enhance new marine industry itself and to enhance its attractiveness as a career, rather than simply increasing the number of related departments. Graduates of related departments will naturally be able to expand the supply of high-quality professional manpower when they feel that new marine industry is the most professionally prospective. In this respect, it is necessary to strive to present the professional vision of new maritime industry professionals. At the same time, in the process of expanding and studying the present status and future prospects of new marine industry from elementary and junior high school students to college students and graduate students, they should be interested in new marine industry and encourage them to prepare for entering new marine industry. There is a need. It would be desirable to put a lot of effort into policies that will allow talented people to be naturally supplied to new marine industries through sufficient publicity. In conclusion, for the sustainable development of the Korean marine industry, we have been given a dual policy task of maintaining the scale of graduate schools related to new marine industries and expanding them if possible, and encouraging graduates to enter the new marine industry.

\section{IMPLICATION}

In this study, we systematically investigate trends and prospects of new marine industry and confirmed the importance and development potential of new marine industry based on various researches. However, due to the characteristics of new marine industry, it is true that many difficulties have been encountered in securing enough data and carrying out quantitative analysis. However, in this difficult situation, it is an important contribution of this study that the demand for mid and long term manpower of new marine industry was quantitatively derived by dividing into 5 areas. It is expected that better results complementing the present study will be expected if the data are accumulated as new marine industries grow, and the result of this study is expected to be a foundation for further research.

According the framework of the study, if the current trend is for universities and graduate schools to be taught, there will be no major problems in terms of supply and demand over the medium to long term. However, the key issue is how to attract marine and non-marine majors to new marine industries. Efforts to create good jobs and public relations projects need to be strengthened. 
Since new marine industry is a new field, it is difficult for customized talent to be supplied directly from existing manpower training system. Therefore, it is necessary to cultivate talented manpower with fused thinking and ability. In the existing system, it is necessary to strengthen efforts to develop professional manpower with fusion competence, and it is also necessary to make policy efforts to build a new system such as cooperation process.

In areas such as new marine industries, the technology life cycle is shorter than retirement age, and professional workers tend to be easily aged and eliminated. In addition, there is a high possibility that demand and supply imbalance among experts in the new industries will occur due to uncertain demand forecasts. In connection with the construction of networks, retraining and field education programs should be strengthened. In particular, it is expected that the effectiveness will be enhanced by establishing and operating information systems for experts in the maritime industry. With this information system, it can be used as a policy, and it can provide useful information to corporations and professional workers. It is anticipated that professional workers will be able to obtain information on their own employment or turnover easily through this system, thereby ensuring stable career management.

\section{REFERENCES}

Acumen, B. (2009). Marine Biotechnology-worldwide trend. Nicolas Bombourg.

The Korea Educational Statistics Service. Access on 22 April 2019, from https://kess.kedi.re.kr/eng/index.

Kim, S.K., Park, S.J., Shin, C., Choi, H., Yook, K.H., Choi, Y., Hong, J., Jung, J., \& Lee, Y.J. (2011). A Study on Securing the Initiative for International Maritime (Basic Research Project Report No. 2010-01). Korea: The Korea Maritime Institute, Busan.

Han, K.W., An, Y., \& Hyun, W. (2013). A Study on the Policy for Education and Training of Marine Science and Technology Professionals (Basic Research Project Report No. 2013-09). Korea: The Korea Maritime Institute, Busan.

Hong, S.M., Eom, M., Kim, H., Hong, J., Song, C.H., Park, J.H., \& Kim, H. (2011). Strategies for Securing Key Science and Technology Personnel to create New Industries (Policy Research Project No. 11-07). Korea: The Science and Technology Policy Institute, Sejong.

Hwang K.H., Park, K., Jang, J.I., Kim, M.S., Park M.J., An, Y., Lee, G.W., \& Lee, J.M. (2011). Establishment of classification system for marine industry and planning study for analysis of role and growth prospect of marine industry (Planning Research Project Report No. 10-096). Korea: The Korea Institute of Marine Science and Technology Promotion, Seoul.

Hwang K.H., Kim, M.S., Park M.J., \& An, Y. (2011). Estimating Gross Ocean Products of Korea with Policy Implication for its Marine Sector (Basic Research Project Report No. 2011-01). Korea: The Korea Maritime Institute, Busan. 